\title{
EVALUATION OF OCULAR INJURIES IN POLYTRAUMA
}

\author{
N. Rama Bharathi' ${ }^{1}$ B. Udaya Kumar ${ }^{2}$, V. Rajeswara Rao ${ }^{3}$, Sidharda ${ }^{4}$, Vaidehi ${ }^{5}$, Vanisree P6, Sreeramachandra Murthy $M^{7}$, Azhar ${ }^{8}$
}

${ }^{1}$ Assistant Professor, Department of Ophthalmology, Andhra Medical College.

2Professor \& Head, Department of Orthopaedics, Andhra Medical College.

3 Professor, Department of Ophthalmology, Andhra Medical College.

${ }_{4}^{4}$ Postgraduate Student, Department of Ophthalmology, Andhra Medical College

${ }^{5}$ Postgraduate Student, Department of Ophthalmology, Andhra Medical College

${ }^{6}$ Assistant Professor, Department of Ophthalmology, Andhra Medical College

${ }^{7}$ Assistant Professor, Department of Ophthalmology, Andhra Medical College

8Postgraduate Student, Department of Ophthalmology, Andhra Medical College.

ABSTRACT

\section{BACKGROUND}

The objective of this study is to evaluate the clinical presentation of ocular injuries in polytrauma cases who attended to OPD of Govt. Regional Eye Hospital, Andhra Medical College, Visakhapatnam.

\section{MATERIALS AND METHODS}

It is a hospital based prospective interventional study from Sep. 2015 to Aug. 2016, in patients who attended emergency or Ophthalmology outpatients department at Regional Eye Hospital. Approval from local ethics committee was obtained to conduct this study. In the present study, total no. of cases of ocular trauma reported to Regional Eye Hospital in this study period were 435 cases, out of which 136 cases (31.26\%) were due to polytrauma \& 299 cases (68.7\%) of ocular trauma were due to other causes. The patient's initial complaints, mode of injury, type of injury as well as the interval between the time of injury and time of presentation, were recorded. The examination findings of the injured eye, the visual acuity, diagnostic tests, investigations and final diagnosis were obtained and recorded according to the standardised classification of ocular trauma.(1,2)

\section{RESULTS}

A total of 145 eyes with ocular injuries in polytrauma cases were analysed, commonest age group involved in accidents was in the age group of 21-30 years. Males were predominantly affected. Most of the patients had sustained subconjunctival haemorrhages, ecchymoses and ocular adnexal injuries rather than penetrating globe injuries involving posterior segment of the eye. The eye ball is protected by bony socket and periorbital structures, which are the first structures to take the impact of the injury during road traffic accidents, so they are more frequently injured rather than posterior segment.

\section{CONCLUSION}

In conclusion, in the current study initial visual acuity after trauma, mode of the injury, presence of RAPD, posterior extent of the wound, presence of vitreous loss adversely affect the final visual outcome. Two wheeler accident is common and an important cause for loss of vision following RTA. In this study out of 145 eyes, most common type of clinical presentation seen was SCH in 73 eyes (50-34\%) followed by ecchymosis in 47 eyes (32.41\%), traumatic cataract in 12 eyes (8.27\%). Cranial nerve involvement was observed in 12 eyes in which traumatic optic neuropathy was seen in 9 eyes (6.2\%), followed by multiple cranial nerve palsy in 2 eyes (16.7\%) and oculomotor nerve palsy in 1 eye (3.3\%). Orbital fractures observed in 35 eyes (24.13\%). Loss of vision due to optic nerve injury had poor visual prognosis. Immediate medical attention and appropriate surgical or nonsurgical conservative medical management will aid in quick visual rehabilitation of the patient especially in open globe injuries.

\section{KEYWORDS}

Ocular Injuries, Polytrauma, Comparative Study.

HOW TO CITE THIS ARTICLE: Bharathi NR, Kumar BU, Rao VR, et al. Evaluation of ocular injuries in polytrauma. J. Evolution Med. Dent. Sci. 2017;6(22):1812-1816, DOI: 10.14260/Jemds/2017/398

\section{BACKGROUND}

Trauma to eye can cause severe and permanent visual impairment owing to its delicate and complex architecture. $(3)$ It is one of the common causes of ophthalmic morbidity and mono-ocular blindness. (4) Worldwide there

Financial or Other, Competing Interest: None.

Submission 21-02-2017, Peer Review 07-03-2017,

Acceptance 10-03-2017, Published 16-03-2017.

Corresponding Author:

Dr. N. Rama Bharathi,

503, Prathima Paradise Apts.,

R. K. Beach Road, Near Hotel Supreme,

Visakhapatnam.

E-mail: ramabharathinela@gmail.com

DOI: $10.14260 /$ jemds $/ 2017 / 398$

are approximately 6 million blind people because of eye injuries. 2.3 million are bilaterally visually impaired \& 19 million are with unilateral visual loss. These facts make ocular trauma the most common cause of unilateral blindness. ${ }^{(5)}$ The most common causes documented for total ocular trauma were motor vehicle accidents.(6) Thus, there is a great need for more active interest in the prevention and immediate treatment of ocular injuries caused by RTA.

Ocular trauma may involve the eye lids, lacrimal canaliculi, orbital wall, periorbital structures, conjunctiva, cornea, sclera, extraocular muscles. In some instances there may be prolapse of uveal tissue, vitreous haemorrhage, choroidal haemorrhage, globe rupture.(7) 


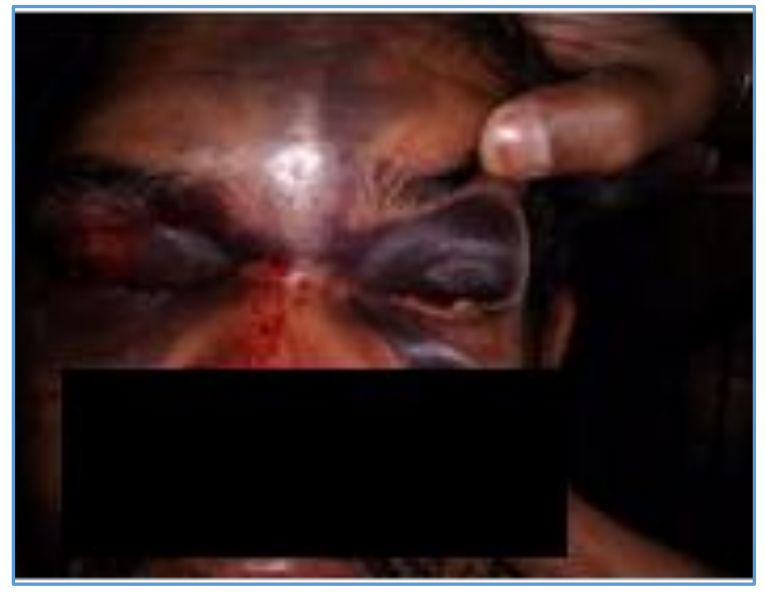

Figure 1. Ecchymosis of Lids

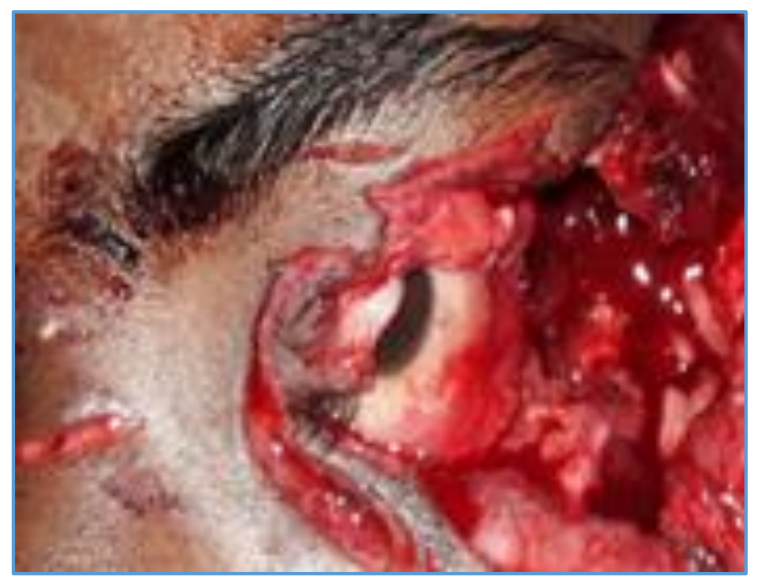

Figure 2. Lateral Orbital Wall Fracture with Intact Globe and Vision

\section{Objective}

To evaluate the clinical presentation of ocular injuries in Polytrauma cases who attended to OPD of Govt. Regional Eye Hospital, Andhra Medical College, Visakhapatnam for a duration of one year.

\section{MATERIALS AND METHODS \\ Exclusion Criteria}

1. Occupational Injuries.

2. Domestic Injuries.

\section{Inclusion Criteria}

Patients who were conscious and unconscious due to head injuries, sports injuries, RTA \& assaults.

\section{Methodology}

It is a Hospital Based Prospective Interventional Study with a study period of 1 year duration, in polytrauma cases who attended to emergency or ophthalmology outpatient department at Regional Eye Hospital, Visakhapatnam with a sample size of 150 patients. Approval from local ethics committee was obtained to conduct this study.

All patients were examined according to the standardised protocol. Data was recorded in the Proforma. Demographic data and details of modes of injury were obtained. The patients' initial complaints, mode of injury, type of injury as well as the interval between the time of injury and time of presentation, were also recorded. The examination findings of the injured eye, the visual acuity, diagnostic tests, investigations and final diagnosis were obtained and recorded according to the standardised classification of ocular trauma. $(8)$

\section{Ophthalmological Examination Included}

- Recording of Visual acuity.

- Slit-lamp examination.

- Indirect Ophthalmoscopy.

- Gonioscopy.

- B Scan Ultrasonography.

- HVF.

- $\quad$ OCT wherever needed.

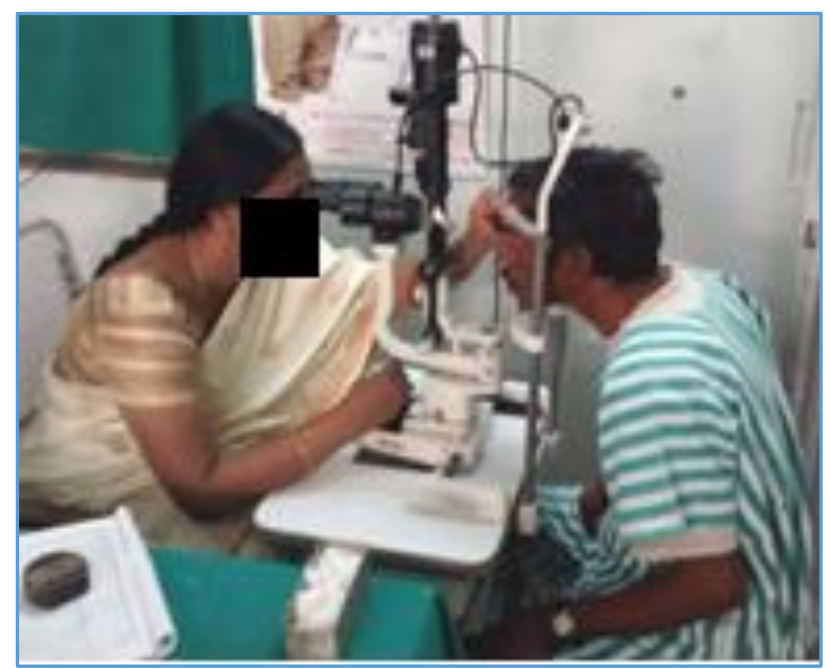

Figure 3. Slit-lamp Examination

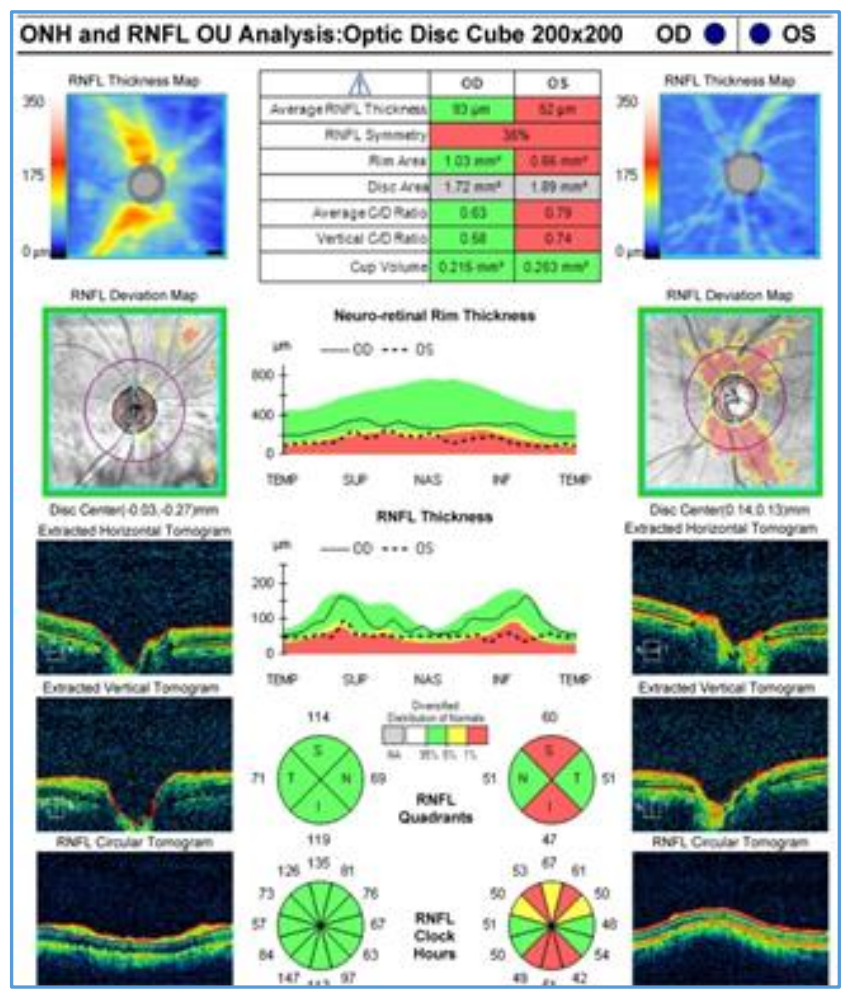

Figure 4. OCT Picture of Traumatic Optic Neuropathy

Routine investigations like Haematological investigations, RBC, Urine (Albumin and sugar), X-Ray of Orbits (AP \& Lateral 
View), CT scan (Brain \& Orbit) \& MRI of Brain wherever appropriate.

\section{RESULTS}

In the present study, most common type of injury was closed Globe injury seen in $62.75 \%$ followed by extraocular injury seen in $32.43 \%$ \& Open Globe Injury in $4.82 \%$.

\begin{tabular}{|c|c|}
\hline Study & Mean age of Presentation \\
\hline Present study & 31.2 \\
\hline Abha et al & 30.57 \\
\hline Kuhn et al & 29 \\
\hline El Shtewi et al & 32.5 \\
\hline \multicolumn{2}{|c|}{ Table 1. Mean Age } \\
\hline
\end{tabular}

\begin{tabular}{|c|c|c|}
\hline Study & Males & Females \\
\hline Present study & $91.9 \%$ & $8.1 \%$ \\
\hline Muralidhar et al & $95 \%$ & $5 \%$ \\
\hline Kumaraswamy et al & $90.3 \%$ & $9.7 \%$ \\
\hline EL Shtewi et al & $75 \%$ & $25 \%$ \\
\hline \multicolumn{2}{|c|}{ Table 2. Gender } \\
\hline
\end{tabular}

\begin{tabular}{|c|c|c|c|}
\hline Study & Right Eye & Left Eye & Both Eyes \\
\hline Present study & $62.5 \%$ & $30.9 \%$ & $6.6 \%$ \\
\hline Panagiotidis et al & $46.3 \%$ & $53.7 \%$ & - \\
\hline Alam et al & $52.1 \%$ & $29.42 \%$ & $18.48 \%$ \\
\hline Ayse Oner et al & $51 \%$ & $44 \%$ & $5 \%$ \\
\hline \multicolumn{4}{|c|}{ Table 3. Laterality } \\
\hline
\end{tabular}

\begin{tabular}{|c|c|c|c|}
\hline Study & $\begin{array}{c}\text { Extra } \\
\text { Ocular } \\
\text { Injury }\end{array}$ & $\begin{array}{c}\text { Closed globe } \\
\text { Injury }\end{array}$ & $\begin{array}{c}\text { Open } \\
\text { Globe } \\
\text { Injury }\end{array}$ \\
\hline Present study & $32.43 \%$ & $62.75 \%$ & $4.82 \%$ \\
\hline Abha et al & $32.79 \%$ & $59.02 \%$ & $8.19 \%$ \\
\hline $\begin{array}{c}\text { Kumaraswamy } \\
\text { et al }\end{array}$ & - & $95.13 \%$ & $4.86 \%$ \\
\hline Vasu et al & - & $61.90 \%$ & $38.10 \%$ \\
\hline Smith et al & - & $68.58 \%$ & $31.41 \%$ \\
\hline \multicolumn{4}{|c|}{ Table 4. Type of Injury } \\
\hline
\end{tabular}

\begin{tabular}{|c|c|}
\hline Study & Orbital Fractures (\%) \\
\hline Present study & $24.13 \%$ \\
\hline Kumaraswamy et al & $22.22 \%$ \\
\hline Cruz et al & $54 \%$ \\
\hline El Shtewi et al & $1.1 \%$ \\
\hline \multicolumn{2}{|c|}{ Table 5. Orbital Fractures } \\
\hline
\end{tabular}

\begin{tabular}{|c|c|c|c|c|}
\hline $\begin{array}{c}\text { Visual } \\
\text { outcome }\end{array}$ & $\begin{array}{c}\text { Present } \\
\text { Study } \\
\text { (2016) } \\
\text { 145 eyes }\end{array}$ & $\begin{array}{c}\text { Abha } \\
\text { et al } \\
\mathbf{( 2 0 1 5 )} \\
\mathbf{1 2 1} \text { eyes }\end{array}$ & $\begin{array}{c}\text { El Shtewi } \\
\text { et al } \\
(\mathbf{1 9 9 9 )}\end{array}$ & $\begin{array}{c}\text { Panagiotidis } \\
\text { et al } \\
\mathbf{( 2 0 0 4 )}\end{array}$ \\
\hline Good (6/18) & $\begin{array}{c}113 \\
(84.96 \%)\end{array}$ & $\begin{array}{c}109 \\
(89.34 \%)\end{array}$ & $\begin{array}{c}169 \\
(61.22 \%)\end{array}$ & $52.5 \%$ \\
\hline $\begin{array}{c}\text { Fair }(6 / 18- \\
6 / 60)\end{array}$ & $\begin{array}{c}21 \\
(14.48 \%)\end{array}$ & $\begin{array}{c}3 \\
(2.46 \%)\end{array}$ & $\begin{array}{c}54 \\
(19.59 \%)\end{array}$ & $13.1 \%$ \\
\hline Poor $(<6 / 60)$ & $\begin{array}{c}11 \\
(8.27 \%)\end{array}$ & $\begin{array}{c}10 \\
(8.20 \%)\end{array}$ & $\begin{array}{c}53 \\
(19.22 \%)\end{array}$ & $29.5 \%$ \\
\hline \multicolumn{5}{|c|}{ Table 6. Visual Outcome } \\
\hline
\end{tabular}

In the present study, total no. of cases of ocular trauma reported to Regional Eye Hospital in this study period were 435 cases, out of which 136 cases (31.26\%) were due to polytrauma \& 299 cases $(68.7 \%)$ of ocular trauma were due to other causes.

In the present study, most common type of injury was closed Globe injury seen in $62.75 \%$ followed by extraocular injury seen in $32.43 \%$ \& Open Globe Injury in $4.82 \%$.

\section{Distribution of Cases According to Incidence}

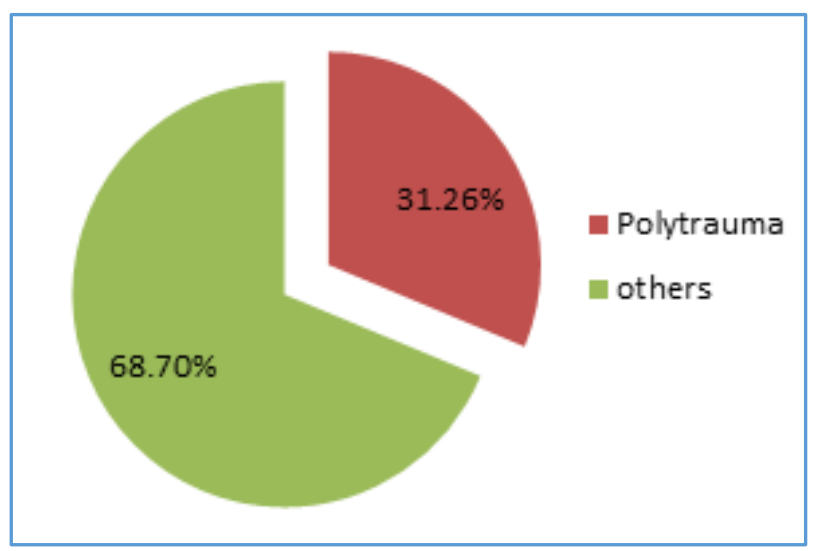

Figure 5. Total Number of Cases

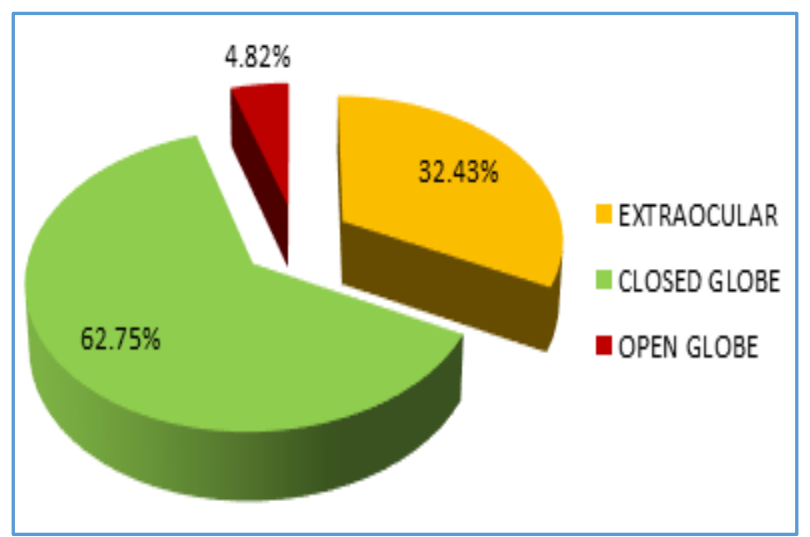

Figure 6. Distribution of Involved Eyes According to Type of Injury

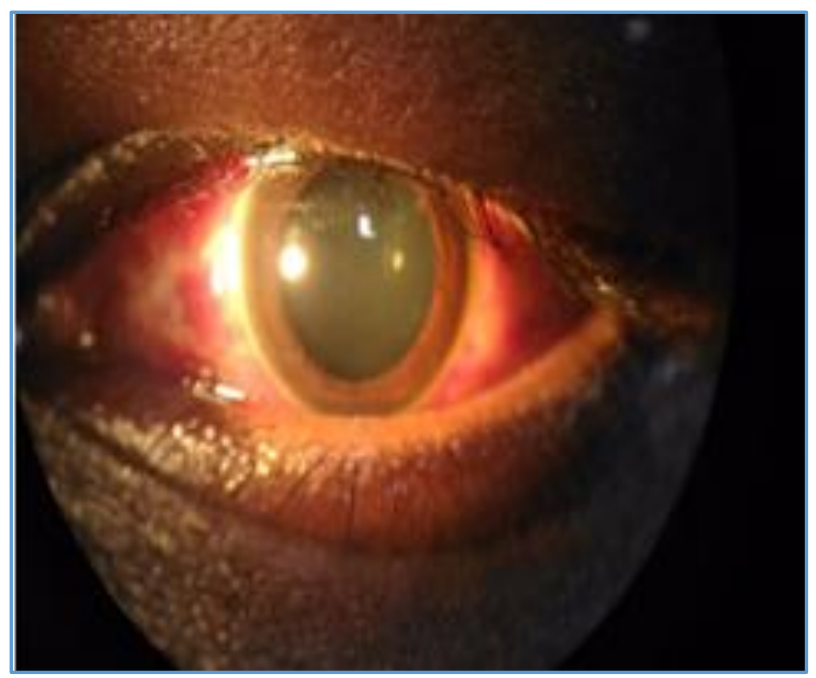

Figure 7. Closed Globe Injury 


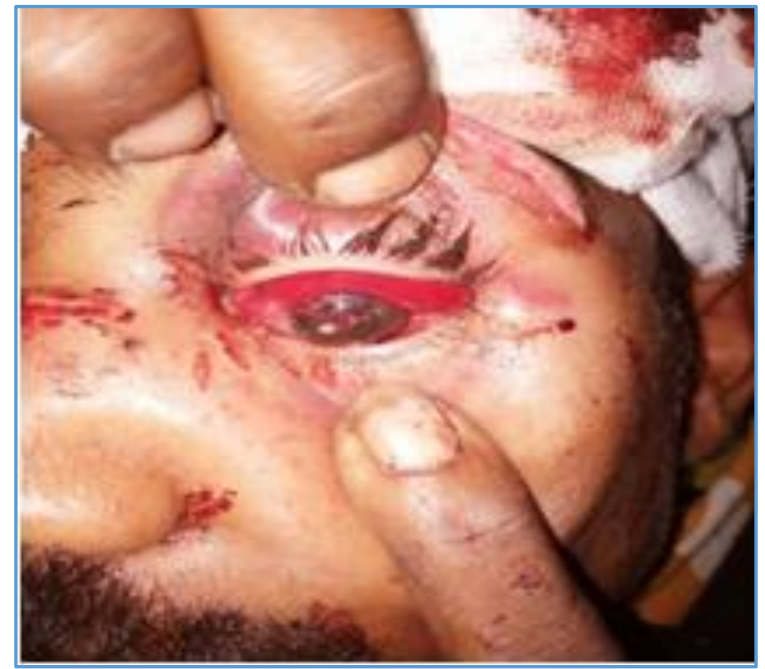

Figure 8. Open Globe Injury

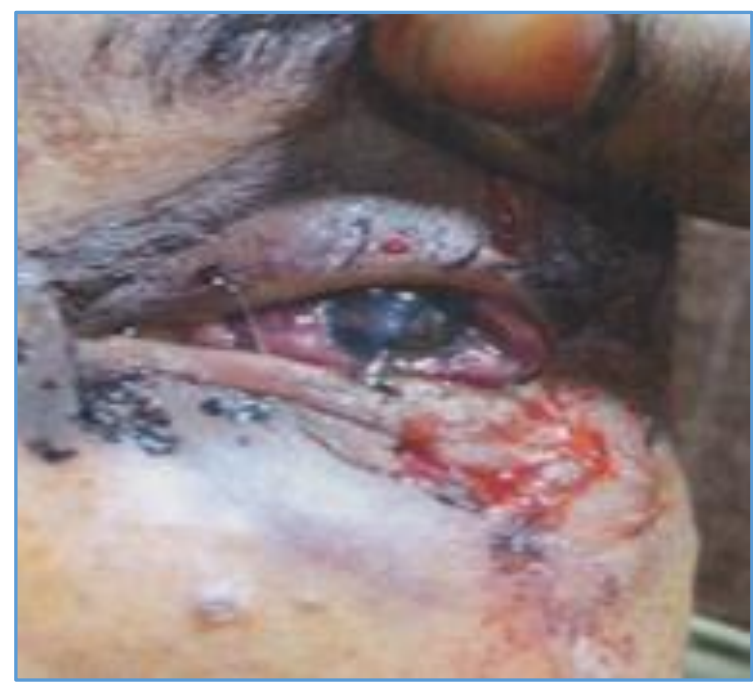

Figure 9. Lid Laceration with Globe Perforation

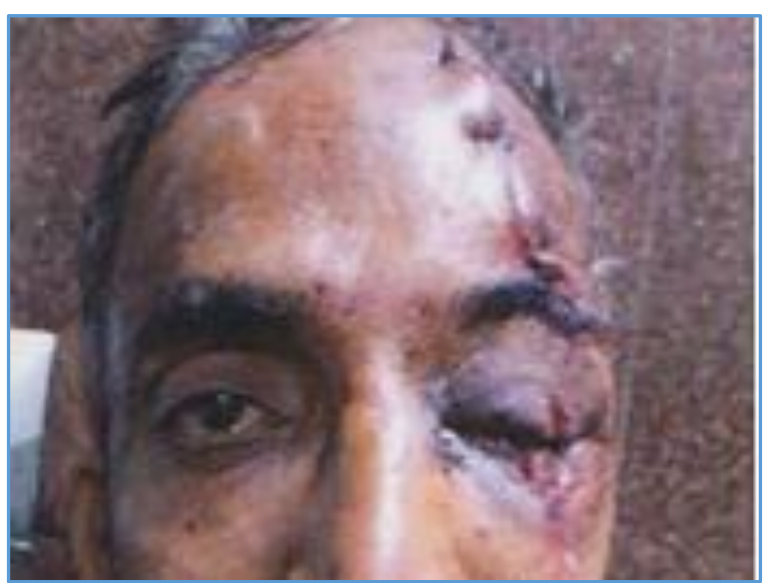

Figure 10. Early Post-operative

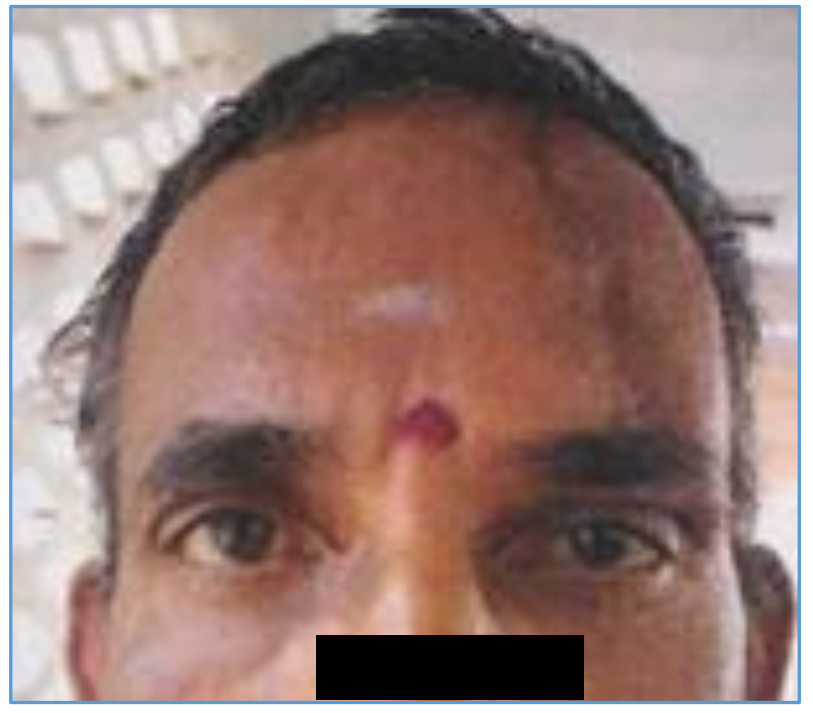

Figure 11. Late Post-operative

\section{DISCUSSION}

Ocular trauma is one of the main causes of blindness and ocular morbidity. It has been shown to be one of the major causes of mono-ocular vision loss, low vision and blindness worldwide with significant socio-economic consequences.

In the present study, it was found that the commonest age group involved in accidents was in the age group of 21-30 years $(39.7 \%)$ and the mean age of ocular trauma was 31.2. Similar findings were reported by Abha et al where the mean age was 30.57 , with more cases seen in the age group of 21-30 years (35\%) \& El Shtewi et al(7) reported the mean age 32.5 \& Kuhn et al in their study of the United States Eye Injury Registry over a seven-year period (1982-1989) found that $61 \%$ of cases between 16-35 years and had a mean age of 29 years. This may be attributed to fact that this is age group which spends most of the time outside.

In the present study males constitutes about 91.9\% (125 cases), females constitutes about $8.1 \%$ (11 cases) with M: F ratio of 13.1:1. These findings are consistent with studies done by Muralidhar et al $\left(^{9}\right)$ \& Kumaraswamy et al(10) whereas study done by El Shtewi et al(7) et al constitutes males about $75 \%$ (186 cases) and females constitute about 25\% (62 cases) as El Shtewi et al is a US based study and males and females both were into driving. The higher incidence of male subjects in road traffic accidents is probably because our population has fewer female drivers/riders and males are more engaged in outdoor activities and are more prone for ocular injuries.

The present study reported involvement of Right Eye in $62.5 \%$, Left Eye in $30.9 \%$ \& Both Eyes in 6.6\%. Panagiotidis et at study showed Right Eye involvement in $46.3 \%$ and Left Eye involvement in $53.7 \%$. In the study done by Alam et al,(11) involvement RE was 52.1\%, LE $29.42 \%$ and both in $18.48 \%$. A study done by Ayse Oner et al showed RE involvement in 51\%, LE involvement in $44 \%$ \& BE in $5 \%$.

In the present study, subconjunctival haemorrhage was seen in 73 eyes (50.34\%) of patients, in comparison to the study by El Shtewi et al(7) in which it was seen in $42.4 \%$. In our study, ecchymosis was seen in 47 eyes (32.41\%) while in the study by El Shtewi et al it was seen in $37.7 \% .9 .65 \%$ of patients in our study had lid laceration, while in the study by El Shtewi et al it was seen in $17.8 \%$. In our study, corneal laceration was seen in 15 eyes $(10.34 \%)$. Similar findings were seen in the studies 
done by Abha et al \& Kumar Swamy et al,(10) while in the study by El Shtewi et al, it occurred in $30.4 \%$ as it has got more number of open globe injuries. In this study, hyphaema was seen in $2.06 \%$ patients whereas Alam et al reported hyphaema $3.36 \%$. Traumatic cataract occurred in $8.27 \%$, Vitreous haemorrhage was seen in $1.37 \%$ of our patients, RD was seen in $0.68 \%$. In a study done by Sumeet Arora et al, injury to lens was seen in $20 \%$ and $\mathrm{VH} / \mathrm{RD}$ seen in $9.33 \%$.

The optic nerve was the most frequently injured of the cranial nerves associated with the eye. This is important, as optic nerve injuries carry a poor visual prognosis; one third of patients in the International Optic Nerve Trauma Study had a final visual acuity of hand movements or worse in the affected eye. Optic nerve injuries were associated with a facial fracture in two thirds of cases. A marked association between orbital fracture and optic nerve injuries in patients with major trauma has been reported previously.(12) The incidence of optic nerve injury in patients with a facial fracture in this study was $6.2 \%$, whereas Guly et al(1) showed incidence of $2.1 \%$ which is similar to that reported by Al-Qurainy et al(2) in their series of patients with mid-facial fractures in the present study, Traumatic Optic Neuropathy was reported in 9 eyes. ${ }^{(6.2 \%)}$ Arora et al[13] reported $18 \%$ of TON \& Alam et al(11) reported $18.6 \%$ TON. Orbital fractures reported in the present study was seen in 35 eyes $(24.13 \%)$. Similar finding was reported by Kumaraswamy et al (22.22\%).(9) In a study done by Cruz et al,(14) orbital fractures accounted up to $54 \%$ while these accounted to $1.1 \%$ in a study done by El Shtewi et al.(7)

Most of the patients had sustained subconjunctival haemorrhages, ecchymoses and ocular adnexal injuries rather than penetrating globe injuries involving posterior segment of the eye. The eye ball is protected by bony socket and periorbital structures, which are the first structures to take the impact of the injury during road traffic accidents, so they are more frequently injured rather than posterior segment; this might be the probable explanation for the type and distribution of injuries seen in present study.

\section{CONCLUSION}

- In the current study, initial visual acuity after trauma, mode of the injury, presence of RAPD, posterior extent of the wound, presence of vitreous loss adversely affect the final visual outcome.

- Two wheeler accident is common and an important cause for loss of vision following RTA.

- In this study, out of 145 eyes most common type of clinical presentation seen was SCH in 73 eyes (50-34\%) followed by ecchymosis in 47 eyes (32.41\%), traumatic cataract in 12 eyes $(8.27 \%)$. Cranial nerve involvement was observed in 12 eyes in which traumatic optic neuropathy was seen in 9 eyes $(6.2 \%)$, followed by multiple cranial nerve palsy in 2 eyes $(16.7 \%)$ \& oculomotor nerve palsy in 1 eye (3.3\%). Orbital fractures observed in 35 eyes (24.13\%).

- Loss of vision due to optic nerve injury had poor visual prognosis.

- Immediate medical attention and appropriate surgical or nonsurgical conservative medical management will aid in quick visual rehabilitation of the patient especially in open globe injuries.

\section{REFERENCES}

[1] Guly CM, Guly HR, Bouamra 0, et al. Ocular injuries in patients with major trauma. Emerg Med J 2006;23(12):915-7.

[2] Al-Qurainy A, Stassen LF, Dutton GN, et al. The characteristics of midfacial fractures and the association with ocular injury: a prospective study. Br J Oral Maxillofac Surg 1991;29(5):291-301.

[3] Ezegwui IR. Eye injuries at Abakaliki, Nigeria. Int J Ophthalmology 2004;4(6):985-8.

[4] Tylefors B. Epidemiologic patterns of ocular trauma. Aust N Z J Opththalmol 1992;20(2):95-8.

[5] Negal AD, Thylefors B. The global impact of eye injuries. Ophthalmic Epidemiol 1998;5(3):143-69.

[6] Soni KG. Eye injuries in road traffic accidents. Injury 1973;5(1):41-6.

[7] Shtewi ME, Shishko MN, Purohit GK. Road traffic accidents and ocular trauma: experience at Tripoli eye hospital, Libya. Community Eye Health 1999;12(29):112.

[8] Kuhn F, Morris R, Witherspoon CD, et al. The Birmingham eye trauma terminology system (BETT). J Fr Ophthalmol 2004;27(2):206-10.

[9] Muralidhar P, Chowdary NL. Ocular manifestations in road traffic accidents: a study done at a medical college hospital in South India. International Journal of Contemporary Medical Research 2016;3(8):2337-9.

[10] Kumarasamy R, Velpandian U, Anandan H. Visual outcome in ocular injuries in road traffic accident. Int J Sci Stud 2016;4(5):151-3.

[11] Alam J, Bhattacharjya H, Roy A, et al. Epidemiology and outcome of ocular trauma among the road traffic accident cases attending a tertiary care hospital in Tripura. Int J Med Sci Public Health 2014;3(4):422-4.

[12] Cole MD, Clearkin L, Dabbs T, et al. The seat belt law and after. Br J Ophthalmol 1987;71:436-40.

[13] De Juan E, Sternberg P, Michels RG. Penetrating ocular injuries. Types of injuries and visual results. Opththalmoloy 1983;90(11):1318-22.

[14] Cruz AA, Eichenberger GC. Epidemiology and management of orbital fractures. Curr Opin Opththalmol 2004;15(5):416-21. 